DOI: $10.5455 / 2320-1770.1 j \operatorname{cog} 20150416$

Research Article

\title{
Critically ill obstetric patients
}

\section{Kirti Rajesh Bendre*, Tanvi Vijay Tuteja, Geeta Madhav Niyogi}

Department of Obstetrics \& Gynecology, K.J. Somaiya Medical College and Research Centre, Mumbai, MS, India

Received: 21 January 2015

Accepted: 16 February 2015

\section{*Correspondence:}

Dr. Kirti Rajesh Bendre,

E-mail: bendrekirti@yahoo.in

Copyright: (C) the author(s), publisher and licensee Medip Academy. This is an open-access article distributed under the terms of the Creative Commons Attribution Non-Commercial License, which permits unrestricted non-commercial use, distribution, and reproduction in any medium, provided the original work is properly cited.

\begin{abstract}
Background: Objectives: To review all obstetric patients admitted in Intensive Care Unit (ICU) to access ethiology, required interventions, maternal mortality and to identify the conditions associated with maternal death.

Methods: This is a retrospective study carried out in a medical college with tertiary hospital facility in Mumbai. The ICU admissions for a period of 5 years from October 2005 to October 2010 were reviewed.

Results: Over 5 years, 48 out of 10800 obstetric patients were admitted in ICU (0.4\%). Most common reasons for admissions were obstetric hemorrhage and preeclampsia. The most common intervention done was transfusion of blood and blood products.

Conclusions: We need better information about high risk obstetrics in order to improve maternal care. The study identifies the risk factors for maternal mortality and severe maternal morbidity, most significant being obstetric hemorrhage. Lack of antenatal care and delay in referral to intensive care unit adversely affect the maternal outcome.
\end{abstract}

Keywords: Intensive care unit, Obstetrics

\section{INTRODUCTION}

Care of a critically ill pregnant woman presents a unique challenge as the patient's disease and therapy simultaneously affects two individuals with vastly different physiologies. It is estimated that approximately $0.7-0.8 \%$ of all pregnant women will develop conditions that would require admission in Intensive Care Unit (ICU). ${ }^{1}$ In India 80000 women lose their lives during the reproductive years with the maternal mortality reaching an appaling high figure of 190 deaths per 100000 live births $^{2,3}$ and many of these women require specialised care which cannot be provided in general ward. ${ }^{4}$ The common causes of maternal mortality are anaemia, hemorrhage, sepsis and toxaemia of pregnancy. Care of these critically ill obstetric patients is a task as these are women who are prone to develop multiorgan failure. Management of such women in a well-equipped ICU improves maternal survival, reducing the mortality to a considerable extent.
This retrospective study was undertaken in a tertiary teaching hospital for a period of 5 years with the aims and objectives of assessing the ethiology, spectrum of disease and interventions required for patients requiring critical care and to identify the causes of maternal mortality.

\section{METHODS}

This study was undertaken in the department of obstetrics and gynecology at a tertiary care hospital and medical college with prior approval from hospital ethics committee and anonymity of patients was preserved. In this 5 year retrospective study from October 2005 to October 2010; 45 pregnant women who were admitted to ICU during pregnancy irrespective of gestational age and within 42 days after delivery were included. Records of these cases were reviewed for details like age, parity, reasons for ICU admission, antepartum/postpartum, preexisting medical disease, medical interventions required, 
duration of ICU stay, maternal outcome after ICU care, mortality and reason for mortality.

\section{RESULTS}

In 5 years there were 9023 obstetric admissions of which $45(0.4 \%)$ women were admitted to ICU. This amounted to $1.5 \%$ of all hospital ICU admissions. Of the 45 admissions; 18 (40\%) were emergency referrals and 27 $(60 \%)$ were booked with our hospital (Figure 1).

$07(15.5 \%)$ were antepartum, 01(2.2\%) were post abortal and $37(82.2 \%)$ were postpartum (Figure 2$)$.

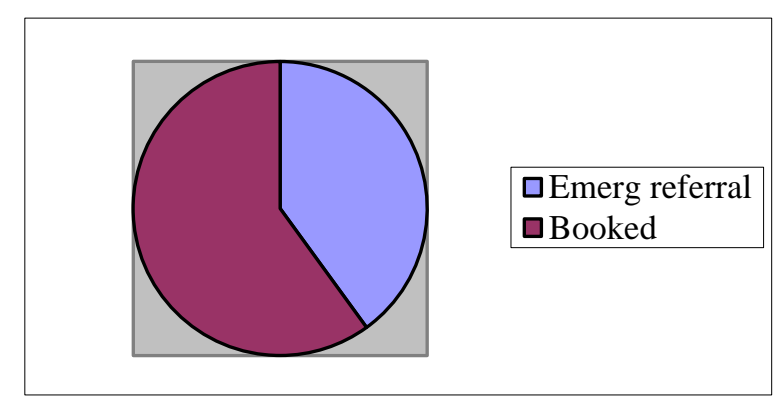

Figure 1: Emergency and booked case.

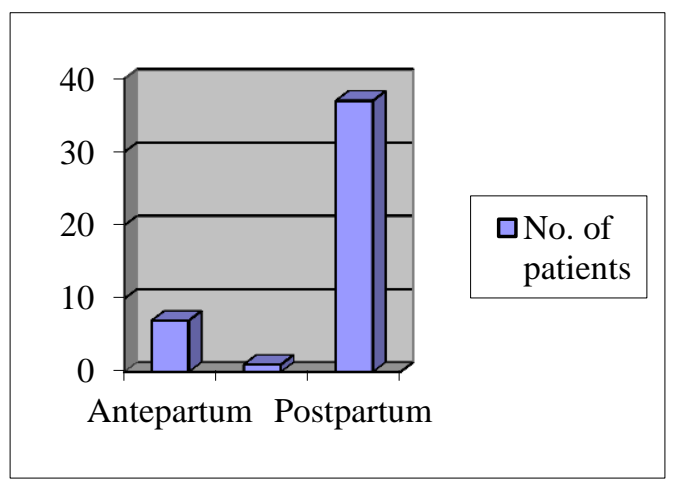

Figure 2: Gestational age.

Mean maternal age was $24.36 \pm 8$ years; the youngest being 19 and eldest 41 years of age (Figure 3). 12 patients $(26 \%)$ were primigravidas. Advancing age affects outcome of critically ill patients and youth confers an advantage for obstetric patients.

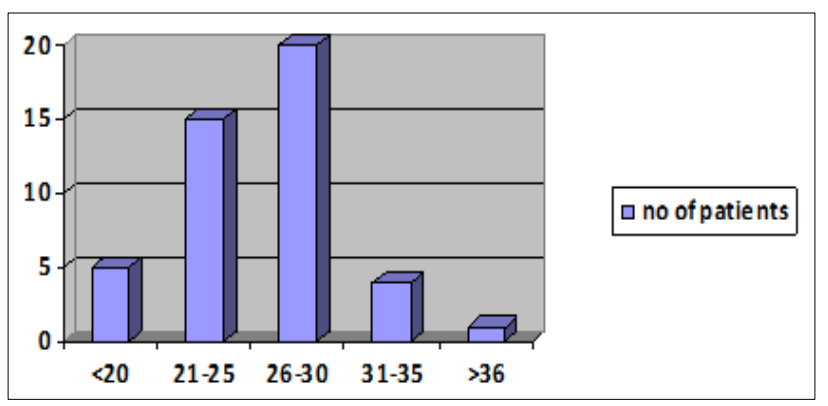

Figure 3: Age wise distribution.
Obstetric hemorrhage was the commonest indication for ICU admission; being present in 19 patients (42.2\%). 15 women $(33.3 \%)$ were shifted to ICU for hypertensive disorders, $6(13.3 \%)$ for intrauterine fetal demise and disseminated intravascular coagulopathy, 3 patients $(6.6 \%)$ for puerperial sepsis, $3(6.6 \%)$ for malaria, 2 (4.4\%) for complications of tuberculosis and 1 (2.2\%) for ARDS and multiorgan failure (Table 1).

Table 1: Cause of ICU admissions.

\begin{tabular}{|lll|}
\hline Cause & $\begin{array}{l}\text { No. of } \\
\text { patients }\end{array}$ & $\%$ \\
\hline Obstetric hemorrhage & 19 & 42.2 \\
\hline Hypertensive disorders & 15 & 33.3 \\
\hline IUFD \& DIC & 06 & 13.3 \\
\hline Sepsis & 03 & 6.6 \\
\hline Malaria & 03 & 6.6 \\
\hline Tuberculosis & 02 & 4.4 \\
\hline ARDS \& multiorgan failure & 01 & 2.2 \\
\hline
\end{tabular}

11 patients $(24.4 \%)$ of women admitted to ICU required ventilator support .Majority of them also required special interventions like multiple transfusions of blood products $(55.5 \%)$, dialysis $(6.6 \%)$, central venous pressure lines $(35.5 \%)$ and vasoactive infusions (15.5) (Table 2).

Table 2: Interventions done.

\begin{tabular}{|ll|l|}
\hline Interventions & $\begin{array}{l}\text { No. of } \\
\text { patients }\end{array}$ & $\%$ \\
\hline Blood \& blood products & 25 & 55.5 \\
\hline Central venous pressure line & 16 & 35.5 \\
\hline Ventilator & 11 & 24.4 \\
\hline Vasoactive infusions & 07 & 15.5 \\
\hline Dialysis & 03 & 6.6 \\
\hline
\end{tabular}

Out of the 45 obstetric admissions in ICU, 9 patients died $(20 \%)$ and remaining were discharged. Most of the maternal deaths were due to multiorgan dysfunction and Disseminated Intravascular Coagulation (DIC).Sepsis and medical disorders like tuberculosis meningitis, cardiac disease were the other causes (Table 3).

Table 3: Cause of death.

\begin{tabular}{|lll|}
\hline Causes & $\begin{array}{l}\text { No. of } \\
\text { patients }\end{array}$ & $\%$ \\
\hline Multiorgan failure with ARDS & 03 & 6.6 \\
\hline DIC & 03 & 6.6 \\
\hline Tubercular meningitis & 01 & 2.2 \\
\hline Myocarditis & 01 & 2.2 \\
\hline Sepsis & 01 & 2.2 \\
\hline
\end{tabular}

\section{DISCUSSION}

The critical care aspects in obstetrics are varied and demand that critical care practitioners have a thorough 
knowledge of fetal and maternal changes in physiology as pregnancy progresses. Pregnancy can affect every organ system and organ specific conditions. ${ }^{4}$ In this study the obstetric patient ICU admission rate was $0.4 \%$. This rate is higher as compared to a multicentric study done by Hazelgrove et al. ${ }^{5}$ where it was $0.17 \%$ which included 14 ICU's in South England over a period of 3 years; but other studies have reported similar rates between 0.3 to $0.7 \% .^{6,7}$

The most common reason for admission in ICU in our study was obstetric hemorrhage $(42.2 \%)$; the second reason was hypertensive disorders that accounted for $33.3 \%$ of all admissions. These are similar to study done by Mahulte et al. and Daniela et al. ${ }^{6,7}$ In our study ICU admission rate due to sepsis was $6.6 \%$ which was low as compared to other studies. 8,9

Most common interventions done in ICU were blood and blood product transfusions $(55.5 \%)$ and central venous pressure line $(35.5 \%)$ which was similar to other studies. $^{5-8}$

In the present study ICU maternal mortality rate was $20 \%$ which is higher compared to mortality rate in developed countries which is $0-12 \%$. ${ }^{(7)} \mathrm{But}$ it is comparable to ICU mortality in various Indian studies which ranges from 43 $63 \% .^{8,9}$

The higher rate can be explained by the fact that $40 \%$ patients were referrals. Majority of them were referred late and in a moribund condition and $33.3 \%$ expired. Majority of complications and deaths are preventable by essential antenatal care at domiciliary and peripheral levels. ${ }^{10}$ Presence of skilled health care staff and trained birth attendants at deliveries result in early referrals in cases of complications and thus prevention of most of the maternal deaths.

\section{CONCLUSION}

Life time chance of having maternal death in developing countries is 1 in 76. Most common causes for maternal deaths are related to obstetric complications, particularly occurring in first 2 days after birth, including post-partum hemorrhage, infections and eclampsia. It is a tragic situation as these deaths are not caused by disease but occurred during or after a natural process.

Availability of good obstetric care is the cornerstone to decrease maternal mortality. Educating women to avail this facility is necessary. Establishment of First Referral Unit (FRU) for management of emergency obstetric patients should be a priority. Early referral to a tertiary care centre coupled with invasive hemodynamic monitoring and ventilator support improves outcome of such patients. Maternal- fetal medicine specialist is a step towards the betterment of such patients. A short period of training of residents and staff in ICU will help managing these patients till they are transferred to tertiary centres.

Funding: No funding sources

Conflict of interest: None declared

Ethical approval: The study was approved by the hospital ethics committee

\section{REFERENCES}

1. Rajab KE, Skerman JH. Obstetric condition requiring intensive admission: a five year survey. The middle East J Emerg Med. 2004;5:1-8.

2. IIPS. National family health survey. International Institute for population sciences, Mumbai. 2013;8(5):226.

3. WHO, UNICEF, UNFPA, the World Bank, and the United Nations Population Division. Trends in maternal mortality: 1990 to 2013. In: WHO, eds. WHO Report. Geneva: World Health Organization; 2014.

4. Naylor DF, Olson MM. Critical care obstetrics and gynecology. Crit Care Clin. 2003;19:127-49.

5. Hazelgrove JF, Price C. Multicentric study of obstetric admission to 14 intensive care units in Southern England. Crit Care Med. 2001;29:770-5.

6. Daniela N, Vasquez, Elisa Etenssoro. Clinical characters and outcomes of obstetric patients requiring ICU admission. Chest. 2007;131:718-24.

7. Mahutte Neal G. Obstetric admissions to the intensive care unit. Obstet Gynecol. 1999;94:263-6.

8. Yuel Veronica Irene, Kaur Vaneet. Critical care in Obstetrics- scenario in a developing country. J Obstet Gynecol India. 2008;58(3):217-20.

9. Nita Dalal, Vivek Patkar, N. Karnik. Critical care in obstetrics. Bombay Hosp J. 1999 July;19:512-4.

10. Sheela CN, Mhaskar A, Mhaskar R. Critical care obstetrics and gynecology. Crit Care Clin. 2003;19:127-49.

DOI: $10.5455 / 2320-1770 . i j r \operatorname{cog} 20150416$

Cite this article as: Bendre KR, Tuteja TV, Niyogi GM. Critically ill obstetric patients. Int J Reprod Contracept Obstet Gynecol 2015;4:370-2. 